\title{
Stress Management in Thin-Film Gas-Permeation
}

\section{Barriers}

Andreas Behrendt ${ }^{l}$, Jens Meyer ${ }^{2}$, Peter van de Weijer ${ }^{3}$, Tobias Gahlmann ${ }^{l}$, Ralf Heiderhoff ${ }^{l}$, Thomas Riedl ${ }^{1}$ *

${ }^{1}$ University of Wuppertal, Institute of Electronic Devices

Rainer-Gruenter-Str. 21, 42119 Wuppertal, Germany

E-mail: t.riedl@uni-wuppertal.de

${ }^{2}$ Philips GmbH, Philipsstrasse 8, 52068 Aachen, Germany

${ }^{3}$ Philips Research, High Tech Campus 7, 5656AE Eindhoven, The Netherlands. 


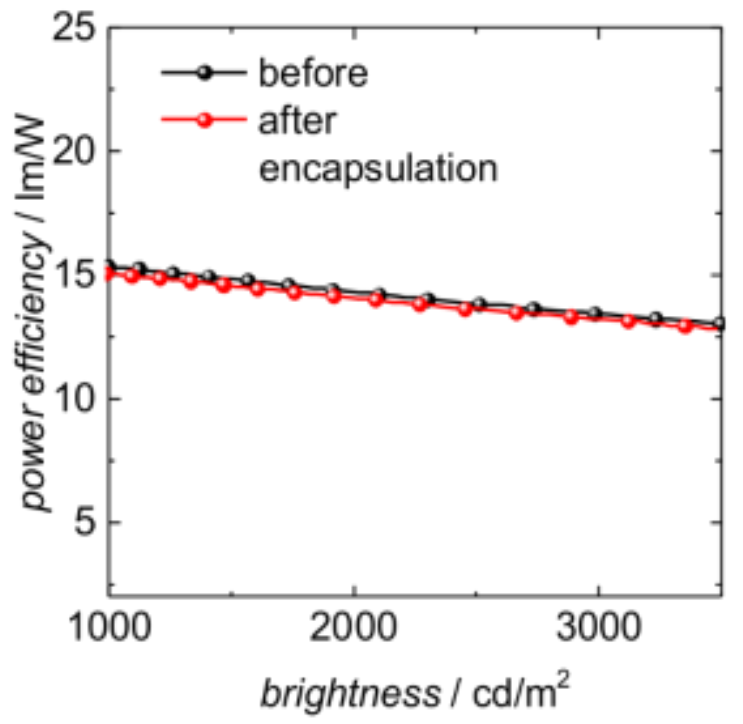

Figure S1 Power efficiency vs. brightness of a white OLED before and after encapsulation with a $100 \mathrm{~nm}$ thick $\mathrm{NL}$ grown at $100^{\circ} \mathrm{C}$.

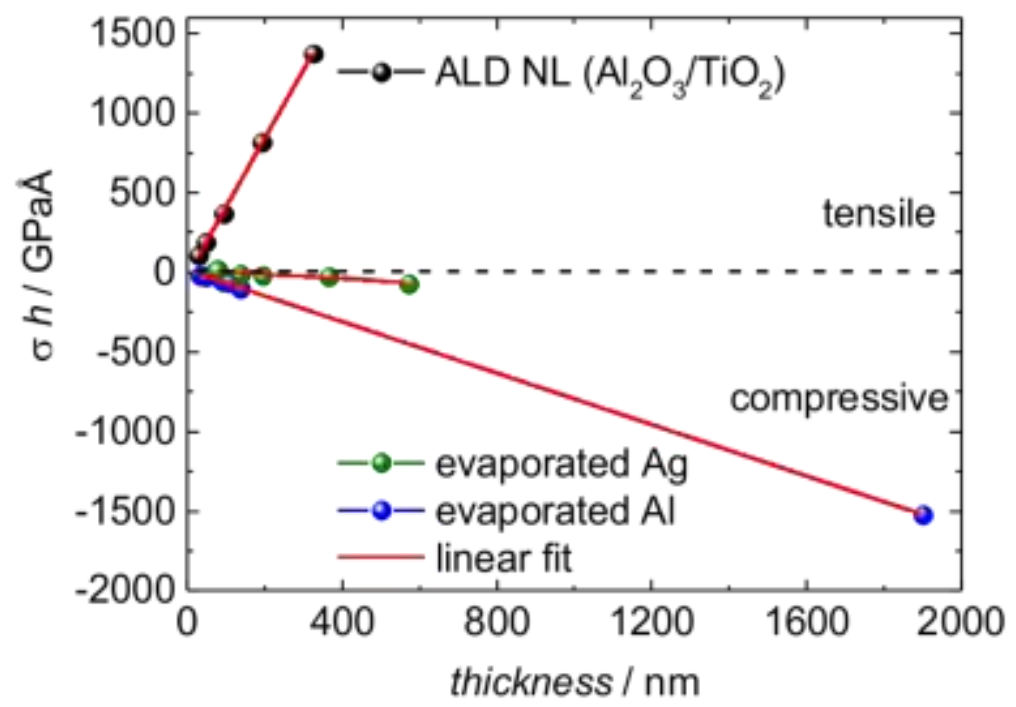

Figure S2 Membrane force $(\sigma \cdot h)$ of ALD grown NL GDBs and thermally evaporated Ag and Al layers vs. layer thickness. The red lines represent a linear fit to the data. 
a

$\mathrm{NL}(500 \mathrm{~nm})$
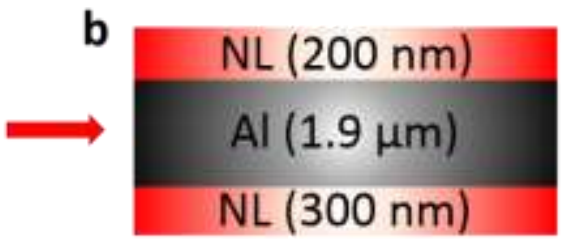

$\sigma \cdot h=2000 \mathrm{GPaA}$

$\sigma \cdot h=740 \mathrm{GPa \AA}$

C

$\mathrm{NL}(360 \mathrm{~nm})$
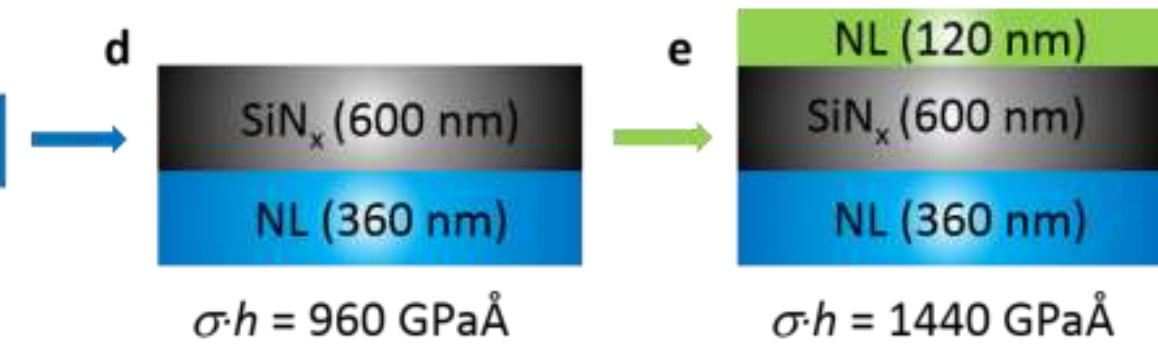

Figure S3 Samples used to test the concept of stress compensation. A $500 \mathrm{~nm}$ thick NL yields a total $(\sigma \cdot h)=2000 \mathrm{GPa} \AA$, which is above the critical level of $1200 \mathrm{GPa} \AA$ (a). Inserting a $1.9 \mu \mathrm{m}$ thick Al layer reduces the total membrane force $(\sigma \cdot h)$ to $740 \mathrm{GPa} \AA$ (b). By a similar token, a $360 \mathrm{~nm}$ thick NL shows a total $(\sigma \cdot h)=1440 \mathrm{GPa} \AA$, which again is above the critical level of $1200 \mathrm{GPa} \AA$ (c). Addition of $600 \mathrm{~nm}$ of $\operatorname{SiN}_{\mathrm{x}}$ on top reduces the total $(\sigma \cdot h)$ to $960 \mathrm{GPa} \AA$ (d). Further deposition of $120 \mathrm{~nm}$ NL on top again increases the total $(\sigma \cdot h)$ to $1440 \mathrm{GPa} \AA$, which again is above the critical level of $1200 \mathrm{GPa} \AA$ (e). The samples shown here and the colors correspond to the colors used in Figure $\mathbf{4} \mathbf{c}$ in the manuscript. 


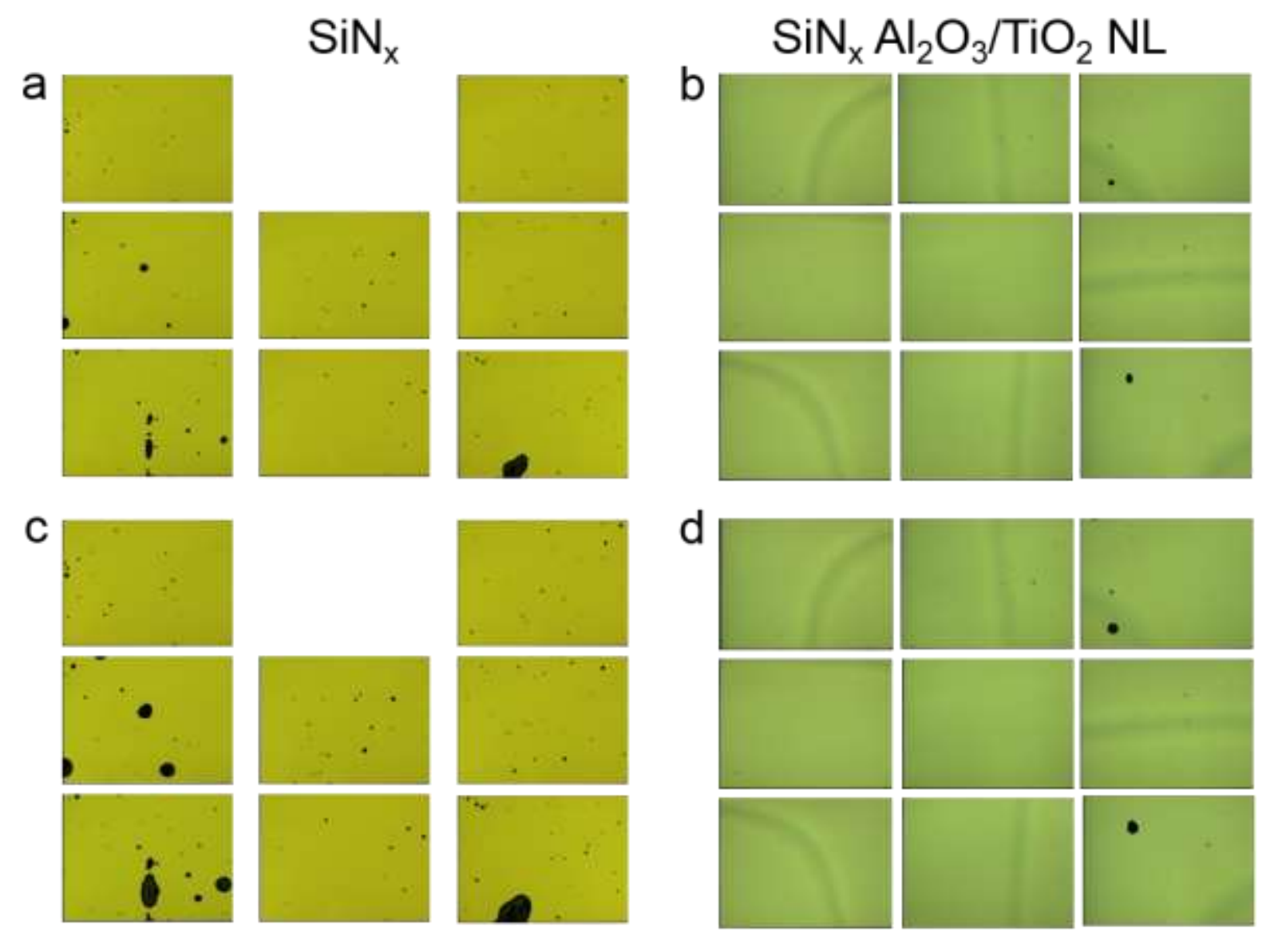

Figure S4 Photographs of OLEDs encapsulated with $600 \mathrm{~nm}$ of $\operatorname{SiN}_{\mathrm{x}}$ (a,c) and with a combination of $600 \mathrm{~nm} \mathrm{SiN}$ and $300 \mathrm{~nm} \mathrm{Al}_{2} \mathrm{O}_{3} / \mathrm{TiO}_{2} \mathrm{NL}(\mathrm{b}, \mathrm{d})$. The OLEDs are stored under damp heat conditions and are operated for dark spot assessment (brightness level of $300 \mathrm{~cd} / \mathrm{m}^{2}$ ). Between (a,b) and (c,d) 24 hours have passed. Please note, one of the $\mathrm{SiN}_{\mathrm{x}}$ samples was broken in the process of separation of the individual OLEDs from the larger $(3 \times 3)$ mother substrate. 